\begin{abstract}
Ruano Nieto $\mathrm{CI}^{\star}$, Melo Perez JD, Mogrovejo Freire LE, De Paula Morales KR and Espinoza Romero CV

Metabolic and Infectious Diseases Unit, Universidad Central del Ecuador, Quito, Ecuador

Dates: Received: 08 September, 2015; Accepted: 13 October, 2015; Published: 15 October, 2015

*Corresponding author: $\mathrm{Dr}$. Ruano Nieto $\mathrm{Cl}$, School of Medicine, Universidad Central del Ecuador, Quito, Ecuador, Iquique N14-121 and Sodiro, Tel: +593 99470-6995; Email: ciruano@uce.edu.ec

www.peertechz.com
\end{abstract}

Keywords: Blood pressure; Hypertension;

Prehypertension; Cardiovascular risk factors

\section{Research Article \\ Hypertension and Cardiovascular Risk Factors in Young University Students from Quito, Ecuador}

\begin{abstract}
Abbreviations
ATP III: Adult Treatment Panel III; AWC: Altered Waist Circumference; BMI: Body Mass Index; BP: Blood Pressure; ENSANUT-ECU: National Health and Nutrition Examination Survey Ecuador; ERICA: Estudio de los Factores de Riesgo Cardiovascular en Adolescentes; IDF: International Diabetes Federation; JNC 7: Joint National Committee on Prevention, Detection, Evaluation, and Treatment of High Blood Pressure; TC: Total cholesterol; UCE: Universidad Central del Ecuador;
\end{abstract}

\section{Introduction}

Nowadays, high blood pressure (hypertension) is the most common non-contagious chronic disease worldwide [1]. It is estimated to cause 7.5 million deaths around the world and about $12.8 \%$ out of all deaths from any other cause [2].

In Ecuador according to data provided by the National Health and Nutrition Examination Survey Ecuador (ENSANUT-ECU) the percentage of pre hypertension in the population among 10-17 years is $14.2 \%$ ( $21 \%$ in the subgroup of $14-17$ years), these values increase to $26.5 \%$ in the group of $18-19$ years [3]. These data show that levels of blood pressure increase with age.

The "Joint National Committee on Prevention, Detection, Evaluation, and Treatment of High Blood Pressure" (JNC 7) in its report classifies as high blood pressure the values above $140 \mathrm{mmHg}$, systolic pressure and $90 \mathrm{mmHg}$ diastolic pressure, while values among $120-139 \mathrm{mmHg}$ (systolic) and $80-89 \mathrm{mmHg}$ (diastolic) indicate a pre hypertension status [4].

High blood pressure is a major risk factor for premature disability and mortality, it directly contributes to the development of heart disease, stroke and renal failure $[1,5]$. High levels of blood pressure are not always presented with clinical symptoms, so early detection of levels outside the ranges established would help to reduce the frequency of cardiovascular events in the future [6].

Overweight, smoking and physical inactivity are strongly related to the deterioration of overall health and are among the most important modifiable risk factors for chronic diseases and premature death [7]. Changes in these factors as increasing exercise levels, lower body weight and quit smoking significantly reduce the BP levels and the hypertension rates $[5,8]$.

Certain cardiovascular risk factors such as obesity, BMI, smoking, alcoholism, diet and sedentary lifestyle, are most frequently involved with blood pressure increase $[9,10]$. Many of these conditions are common in young people and adolescents around the world, so the risk of hypertensive disorders is higher [10]. It is important to identify young population with a previous stage of hypertension (prehypertension), whereas in adults the risk of cardiovascular disease increases with this condition [6].

The apparently "healthy" university students can present 
predisposing factors for cardiovascular disease, prehypertension and hypertension risk without obvious clinical manifestations. Because many of these factors are modifiable, it is important to know the local situation and establish opportune intervention programs $[11,12]$.

The aim of this study was to determine the prevalence of prehypertension and hypertension in young university students from the UCE and the association with cardiovascular risk factors.

\section{Materials and Methods}

Epidemiological, analytical, cross-sectional study. Risk factors associated with the prevalence of metabolic syndrome, including pre hypertension and hypertension values were determined.

All students enrolled in first, second and third semester of the Medicine School, Faculty of Medical Sciences of the UCE, period October 2014 March 2015 were invited to voluntarily participate in the pre-signed aware consent (Approved by the Ethics Committee of the Faculty of Medical Sciences of the UCE). The studies were performed in a doctor's office specially designed for that purpose in the Faculty of Medical Sciences of UCE. All of the students answered a survey in which information on personal data, personal medical history, family medical history, eating habits, alcohol and cigarette consumption, and exercise practice was collected. BMI was calculated and waist circumference and BP was measured. BMI was determined using a balance with a stadiometer of SECA brand (new, and factory calibrated). The students were weighed and measured in light clothing and no shoes. The abdominal circumference was measured with a tape measure according to international standards. The BP was measured using a mercury sphygmomanometer Riester brand (new and factory calibrated) by a single researcher previously trained to avoid inter-take variations. Prior a break of at least 5 minutes, the BP was measured with the student in sitting position, placing the sleeve on the left forearm for the purpose of standardization. If the values of BP presents some alteration on the first take was measured for the second time after 10 minutes repose. Blood pressure was taken as a part of Metabolic Syndrome diagnosis and it was taken only one time. The value used was the average between the two samples. The diagnosis of hypertension was performed using those criteria recommended by the ATP III and IDF for age [13] and values established by the JNC 7 [4].

All of the students were appointed by pre-established appointments in the morning with 12 -hour fast, a sample of venous blood from the elbow crease was extracted from which the plasma was separated. Blood chemistries including urea, glucose, creatinine, uric acid, lipid profile: total cholesterol (TC), triglycerides, HDL, were determined using a Roche Modular with P-800 analyzer with the colorimetric enzymatic method; LDL was calculated using the Fried wall equation. The cutoff points for each variable established were taken by the OMS and IDF [13].

Students who do not perform physical activity at least 3 times (days) a week were classified as sedentary, smokers those who consumed at least one cigarette a week and as consumers of alcohol to those who did it at least once a month.

A database in Microsoft Excel 2007 and statistical analysis were made using SPSS 21 . The results are presented in tables and graphs. The Statistical tests used were: measures of central tendency, confidence intervals at $95 \%$, chi $\mathrm{x}^{2}, \mathrm{~T}$ and $\mathrm{U}$ test and Mann Whitney, ANOVA, Pearson correlation and association measures Odds Ratio, with its values of $p$, cutoff points which were taken from OMS and IDF and laboratory reference values that perform the samples analysis.

\section{Results}

883 college students of $17-25$ years were included in the study with an average age of $19.3 \pm 1.4,63.3 \%$ who were female and $36.7 \%$ were male.

$15.2 \%(n=134)$ of the population presented a BP $>130 / 85$ (Table $1)$, the $9.51 \%(\mathrm{n}=84)$ had elevated systolic BP while diastolic BP was elevated in $9.1 \%(\mathrm{n}=81)$ (Figure 1).

If we consider the JNC 7 cutoff points the prevalence of hypertension (> 140/90) was $3.7 \%$ and prehypertension (120-139/ $80-89)$ of $33.9 \%$. Students with normal BP $(<120 / 80)$ were $62.4 \%$.

Table 1 shows the characteristics of the study population, weight, height, BMI and BP values. Comparing the average of male and female groups, statistically significant differences were found regarding weight and height $(\mathrm{p}<0.05)$. In relation to $\mathrm{BP}$, both systolic and diastolic $(\mathrm{p}<0.05)$ values had significantly higher averages in males. Values of BMI had no statistical significant difference.

Based on the BMI, it was found that one out of four students tested had some degree of overweight (BMI: 25-30) or obesity (BMI > 30). $22.3 \%$ of the population $(\mathrm{n}=197)$ were overweight and $3.2 \%$ $(\mathrm{n}=28)$ obesity.

Table 1: General characteristics of the study population by gender.

\begin{tabular}{|c|c|c|c|c|}
\hline & Total $\mathbf{( n = 8 8 3 )}$ & $\begin{array}{c}\text { Female } \\
(\mathbf{n = 5 5 9})\end{array}$ & $\begin{array}{c}\text { Male } \\
\mathbf{( n = 3 2 4 )}\end{array}$ & $\mathbf{P}$ \\
\hline Age & $19.3 \pm 1.4$ & $19.3 \pm 1.4$ & $19.3 \pm 1.4$ & $\mathrm{p}>0.05$ \\
\hline Weight $(\mathrm{Kg})$ & $61.0 \pm 10.8$ & $57.2 \pm 8.8$ & $67.6 \pm 10.9$ & $\mathrm{p}<0.05$ \\
\hline Height $(\mathrm{m})$ & $1.61 \pm 0.08$ & $1.57 \pm 0.06$ & $1.69 \pm 0.06$ & $\mathrm{p}<0.05$ \\
\hline BMI & $23.3 \pm 3.2$ & $23.15 \pm 3.06$ & $23.57 \pm 3.38$ & $\mathrm{p}>0.05$ \\
\hline Systolic BP & $116.1 \pm 11.1$ & $114.2 \pm 10.0$ & $119.8 \pm 11.8$ & $\mathrm{p}<0.05$ \\
\hline Diastolic BP & $73.2 \pm 8.5$ & $71.9 \pm 8.0$ & $75.5 \pm 8.8$ & $\mathrm{p}<0.05$ \\
\hline
\end{tabular}

Abbreviations: BMI: Body mass idex; BP: Blood pressure.

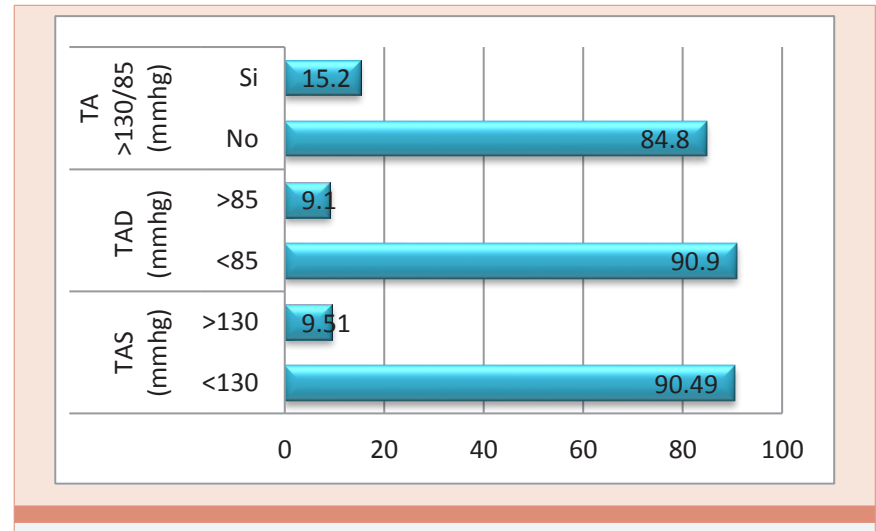

Figure 1: Prevalence of BP altered $(>130 / 85 \mathrm{mmHg})$ in the general population. 
For those students who presented altered waist circumference (AWC) define as $>90 \mathrm{~cm}$ in man and $>80 \mathrm{~cm}$ in woman, a tendency to increase in systolic and diastolic BP $(\mathrm{P}<0.05)$ was evidenced, likewise if we compare those with overweight and obesity versus those with normal BMI, an increased in systolic and diastolic BP was found in the first ones which was statistically significantly $(\mathrm{p}<0.05)$ (Table 2$)$.

Regarding the results of biochemical tests, relating the values of the lipid profile with the BP, only hypertriglyceridemia (> $150 \mathrm{mg} /$ dl) increased systolic BP, the difference was significant, which did not happen with the diastolic BP. There were no significant changes in the values of cholesterol, HDL, LDL and BP (Table 2).

In relation to consumption of cigarette and alcohol intake in young people who consumed at least one cigarette a week and drank alcohol at least once a month, a slight increase in systolic and diastolic BP ( $p<0.05)$ was found. Despite of the large prevalence found, sedentary lifestyle did not influence the values of BP (Table 2).

The risk of developing hypertension was statistically significant
( $\mathrm{p}<0.05)$ in men with an OR of 2.95 (2.02 to 4.30) (Table 3). The risk factors associated with increased of $\mathrm{BP}$ were the altered waist circumference, OR 1, 94 (1.34 to 2.82), in hypertriglyceridemia, which is itself a risk factor, OR 1.68 (1.01 to 2.82), and body mass index altered, OR 3, 09 (2.11 to 4.53), which showed to be the biggest risk factors found. In the other parameters evaluated, this difference was not statistically significant (Table 3 ).

\section{Discussion}

In the present study, the gender, BMI and the BP were the principal risk factors for developing hypertension and pre-hypertension in both male and female in our study group.

The prevalence of hypertension was $15.2 \%$ (IDF) and $3.7 \%$ (JNC 7). Also, it calls the attention the high prevalence of prehypertension (33.9\%), higher in male. This is similar to data found in studies made in Brazil in which it was found a 3.3\% [14], with a higher prevalence in males, in Peru with a prevalence of $1.4 \%$ [15], and in Colombia with a prevalence of $3.8 \%$ of prehypertension and $3.2 \%$ of hypertension in

Table 2: Average systolic and diastolic BP according to gender and cardio vascular risk factors.

\begin{tabular}{|c|c|c|c|c|c|}
\hline & & SYSTOLIC BP & $\mathrm{p}$ & DIASTOLIC BP & $\mathrm{P}$ \\
\hline \multirow{2}{*}{ WC $(\mathrm{cm}):>80$ Female; $>90$ male } & Altered & $117.9 \pm 10.7$ & \multirow[b]{2}{*}{$p<0.05$} & $74.3 \pm 8.6$ & \multirow[b]{2}{*}{$p<0.05$} \\
\hline & Normal & $114.9 \pm 11.1$ & & $72.4 \pm 8.4$ & \\
\hline \multirow{2}{*}{ HDL $(\mathrm{mg} / \mathrm{dl}):<50$ Female $;<40$ male } & Altered & $116.1 \pm 10.9$ & \multirow[b]{2}{*}{$p>0.05$} & $73.4 \pm 8.5$ & \multirow[b]{2}{*}{$p>0.05$} \\
\hline & Normal & $116.2 \pm 11.9$ & & $73.2 \pm 8.5$ & \\
\hline \multirow{2}{*}{ Triglycerides (mg/dl) } & $>150$ & $118.6 \pm 11.3$ & \multirow[b]{2}{*}{$p<0.05$} & $74.8 \pm 9.4$ & \multirow[b]{2}{*}{$p>0.05$} \\
\hline & $<150$ & $115.8 \pm 11.0$ & & $73.0 \pm 8.4$ & \\
\hline \multirow{2}{*}{ Alcohol intake } & Yes & $117 \pm 10.7$ & \multirow[b]{2}{*}{$p<0.05$} & $73.8 \pm 8.5$ & \multirow[b]{2}{*}{$\mathrm{p}<0.05$} \\
\hline & No & $115 \pm 11.4$ & & $72.6 \pm 8.5$ & \\
\hline \multirow{2}{*}{ Cigarette consumption } & Yes & $119 \pm 10.3$ & \multirow[b]{2}{*}{$p<0.05$} & $74.1 \pm 7.9$ & \multirow[b]{2}{*}{$p>0.05$} \\
\hline & No & $115.7 \pm 11.1$ & & $73.1 \pm 8.6$ & \\
\hline \multirow{2}{*}{ BMI (kg/m2) } & $<24.99$ & $114.7 \pm 10.8$ & \multirow[b]{2}{*}{$p<0.05$} & $72.3 \pm 8.4$ & \multirow[b]{2}{*}{$p<0.05$} \\
\hline & $>25.00$ & $120.2 \pm 10.8$ & & $75.9 \pm 8.4$ & \\
\hline \multirow{2}{*}{ Sedentary lifestyle } & Yes & $115.9 \pm 11.1$ & \multirow[b]{2}{*}{$p>0.05$} & $73.0 \pm 8.5$ & \multirow[b]{2}{*}{$p>0.05$} \\
\hline & No & $117.0 \pm 10.4$ & & $74.3 \pm 8.4$ & \\
\hline
\end{tabular}

Abbreviations: BMI: Body mass index; BP: Blood pressure; HDL: High density lipoprotein; WC: Waist circumference.

Table 3: Elevated BP (> 130/85 mmHg) according to gender and cardiovascular risk factors

\begin{tabular}{|c|c|c|c|c|c|c|c|}
\hline & & \multicolumn{4}{|c|}{$B P>130 / 85 \mathrm{mmhg}$} & \multirow{3}{*}{ OR (IC 95\%) } & \multirow{3}{*}{$\mathbf{p}$} \\
\hline & & \multicolumn{2}{|c|}{ Altered } & \multicolumn{2}{|c|}{ Normal } & & \\
\hline & & "n" & $\%$ & "n" & $\%$ & & \\
\hline \multirow[t]{2}{*}{ Gender } & Male & 79 & $24.40 \%$ & 245 & $75.60 \%$ & \multirow{2}{*}{$\begin{array}{c}2.95 \\
(2.02-4.30)\end{array}$} & \multirow{2}{*}{$p<0.05$} \\
\hline & Female & 55 & $9.80 \%$ & 504 & $90.20 \%$ & & \\
\hline \multirow{2}{*}{$\begin{array}{l}\text { WC }(\mathrm{cm}) \\
>80 \text { Female } \\
>90 \text { male }\end{array}$} & Altered & 76 & $20.20 \%$ & 301 & $79.80 \%$ & \multirow{2}{*}{$\begin{array}{c}1.94 \\
(1.34-2.82)\end{array}$} & \multirow{2}{*}{$p<0.05$} \\
\hline & Normal & 58 & $11.50 \%$ & 447 & $88.50 \%$ & & \\
\hline \multirow{2}{*}{$\begin{array}{l}\mathrm{HDL}(\mathrm{mg} / \mathrm{dl}) \\
>50 \text { female } \\
>40 \text { male }\end{array}$} & Altered & 43 & $15.40 \%$ & 237 & $84.60 \%$ & \multirow{2}{*}{$\begin{array}{c}1.02 \\
(0.68-1.51)\end{array}$} & \multirow{2}{*}{$p>0.05$} \\
\hline & Normal & 91 & $15.10 \%$ & 512 & $84.90 \%$ & & \\
\hline \multirow[t]{2}{*}{ Triglycerides (mg / dl) } & $>150$ & 22 & $22.00 \%$ & 78 & $78.00 \%$ & \multirow{2}{*}{$\begin{array}{c}1.68 \\
(1.01-2.82)\end{array}$} & \multirow{2}{*}{$p<0.05$} \\
\hline & $<150$ & 112 & $14.30 \%$ & 671 & $85.70 \%$ & & \\
\hline \multirow[t]{2}{*}{ Alcohol intake } & Yes & 79 & $17.20 \%$ & 380 & $82.80 \%$ & \multirow{2}{*}{$\begin{array}{c}1.39 \\
(0.96-2.02)\end{array}$} & \multirow{2}{*}{$p>0.05$} \\
\hline & No & 55 & $13.00 \%$ & 369 & $87.00 \%$ & & \\
\hline \multirow[t]{2}{*}{ Cigarette consumption } & Yes & 20 & $19.00 \%$ & 85 & $81.00 \%$ & \multirow{2}{*}{$\begin{array}{c}1.37 \\
(0.80-2.31)\end{array}$} & \multirow{2}{*}{$p>0.05$} \\
\hline & No & 114 & $14.70 \%$ & 664 & $85.30 \%$ & & \\
\hline \multirow{2}{*}{ BMI (kg / m2) } & $>25.00$ & 62 & $27.60 \%$ & 163 & $72.40 \%$ & \multirow{2}{*}{$\begin{array}{c}3.09 \\
(2.11-4.53)\end{array}$} & \multirow{2}{*}{$p<0.05$} \\
\hline & $<24.99$ & 72 & $10.90 \%$ & 586 & $89.10 \%$ & & \\
\hline
\end{tabular}

Abbreviations: BMI: Body mass index; BP: Blood pressure; HDL: High density lipoprotein; WC: Waist circumference. 
a sample of 2807 adolescents [16]. The ERICA study showed elevated blood pressure numbers in $14.9 \%$ of adolescents [17]. In the United States, it was found a prevalence of $24.4 \%$ in young adults [18]. The overall prehypertension prevalence in freshman students in a Spanish study was $24 \%$ (95\% CI: $21-27 \%$ ): $56.5 \%$ male and $13.0 \%$ female [19], which is far below the values found by our group.

It is known that weight gain is the result of interaction between genetic factors and an environment that promotes a sedentary lifestyle and high calorie intake. Overweight adolescents have 70\% probabilities to become overweight or obese adults, which increases to $80 \%$ if one or both parents are obese or overweight [20]. In recent decades, overweight and obesity in young adolescent population have been increased which suggests an increasing in cardiovascular risk.

The current study found that $22.3 \%$ of the population was overweight and $3.2 \%$ obese which is consistent with the data found in national health and nutrition survey (ENSANUT) made by the Public Health Ministry of Ecuador in which the prevalence of pre obesity and obesity in adolescents from 12 to 19 years old is $26 \%$, but it is much lower than that one found in population from 19 to 60 years old (62.8\%) [3], which means that in our population pre obesity and obesity significantly increase with age and there is no significant difference by gender. Similar data were found in a Chilean study (23.4\%, 5.2\%) [21]. Two Cuban studies reported data regarding the topic, in the first one $13.9 \%$ of adolescent were overweight and $9.3 \%$ were obese [22], and in the other one in young people from 12 to 19 years old, obesity was found in $16.9 \%$ [23]. Other authors reported that $17.5 \%$ and $16.4 \%$ of the young people evaluated were overweight or obese [24], these three studies present lower numbers than the ones found in the present work. However, other studies revealed that $40 \%$ of adolescents studied, presented overweight, of whom $28 \%$ showed overweight and $12 \%$ were obese [25]. Another study made in Mexico found $35.26 \%$ and $15.80 \%$ of overweight and obesity respectively [26] a fact which shows a higher prevalence of obesity in relation to the data found in this study.

Overall in this study, the prevalence of hypertension in people with altered BMI (greater than 25) was $27.6 \%$ compared to the $72.4 \%$ of students with normal BMI, these data are similar to those found in 1,500 students of a medical university in Athens, whose people consume a Mediterranean diet, in which the prevalence of hypertension was higher in overweight and obese subjects compared with subjects who had normal weight [27]. Thus we can conclude that the pre obesity and obesity constituted the main risk factors for developing hypertension (OR 3.09; 95\%; CI: 2.11-4.53) similar to the Greek study (OR, 4.71; 95\% CI: 3.17-7.00).

It has been proven that waist circumference or abdominal perimeter in young adolescents is a good predictor of metabolic complications and cardiovascular risk [28]. In the present study, AWC among female population was $33.67 \%$ comparing with a $9.55 \%$ in male subjects which is consistent with data found in the Chilean study in which the waist circumference was significantly higher in women [21]. Waist circumference data are directly related to those obtained in relation to the sedentary lifestyle, also higher in women. These data is similar to the Mexican study [26] and the National
Health Survey - Chile realized in similar population [29]. These results demonstrate that the waist circumference is a good indicator of central obesity with clinical and epidemiological utility [28]. In this study, the risk that subjects with AWC could present hypertension was OR 1.94; 95\%; CI: $1.34-2.82$ compared to those who present a unaltered waist circumference.

On the other hand, the results of this current study show that there were no significant differences in BP among young smokers and non-smokers and in those ones who consume alcohol and who do not, which is consistent with some studies that show no significant associations between BP and young people smoking [27,30,31], demonstrating that the effects in biochemical and hemodynamic levels are probably caused by chronic consumption of cigarettes and alcohol.

\section{Conclusion}

According to the results of this study, gender (male), body mass index and waist circumference were directly associated with increase in both, systolic and diastolic blood pressure in young adults in the university, thus it is necessary to carry out early intervention programs to improve the lifestyle of young people which would be useful to control major risk factors and thereby to reduce the prevalence of hypertension, preventing the development of other cardiovascular diseases, metabolic syndrome, and diabetes. It is necessary to make new research in order to examine the association between smoking, alcohol consumption and physical activity, as well as other risk factors associated with changes in blood pressure in young people.

NETLAB SA, clinical laboratory accredited under ISO 15189 international standards and CERTIFICATION LIPIDS STANDARDIZATION PROGRAM CDC Atlanta.

\section{Acknowledgement}

To the first, second and third semester students of the October 2014- March 2015 period of the Medicine Faculty of the Medical Sciences School of the Central University of Ecuador.

\section{References}

1. Fuentes OM, Alonso EC, Bárbara B, Rodríguez C, Martínez MP (2014) Hidden morbidity by arterial hypertension in adolescents. Revista de Ciencias Médicas de La Habana 20: 308-319.

2. World Health Organization (2013) A global brief on hypertension. Silent killer, global public health crisis. Geneva 2013.

3. Encuesta Nacional de Salud y Nutrición ENSANUT (2013) Ministerio de Salud Pública de la República del Ecuador

4. Chobanian AV, Bakris GL, Black HR, Cushman WC, Green LA, et al. (2004) The Seven Report of the Joint National Committee on Prevention, Detection, Evaluation and Treatment of High Blood Pressure: The JNC 7 Report. JAMA 289: 2560-2571.

5. Mancia G, Fagard R, Narkiewicz K, Redón J, Zanchetti A, et al. (2013) ESH/ ESC guidelines for the management of arterial hypertension: the Task Force for the Management of Arterial Hypertension of the European Society of Hypertension (ESH) and of the European Society of Cardiology (ESC). J Hypertens 31:1281-1357.

6. Ortiz-Galeano I, Franquelo-Morales P, Notario-Pacheco B, Nieto JB, Ungría $\mathrm{MV}$, et al. (2012) Prehipertensión arterial en adultos jóvenes. Rev Clin Esp 212: $287-291$. 
7. Strong K, Mathers C, Leeder S, Beaglehole R (2005) Preventing chronic disease: how many lives can we save? Lancet 366: 1578-1582.

8. Kokkinos PF, Giannelou A, Manolis A, Pittaras A (2009) Physical activity in the prevention and management of high blood pressure. Hellenic $\mathrm{J}$ Cardio 50: 52-59.

9. Álvarez MF, Alzate AV, Campos CA, Giraldo MF, Hachito J, et al. (2010) Exploración inicial de los valores de tensión arterial y factores de riesgo asociados a hipertensión arterial en estudiantes de la Universidad de Manizales, Colombia en el 2009. MéD.UIS 23: 207-215.

10. Papathanasiou G, Zerva E, Zacharis I, Papandreou M, Papageorgiou E, et al. (2015) Association of High Blood Pressure with Body Mass Index, Smoking and Physical Activity in Healthy Young Adults. Open Cardiovasc Med J 9 : 5-17.

11. Norkela S (2013) Clinical approach to young hypertension. Brunei Int Med J 9: 81-92.

12. Morales GI, Del Valle CR, Soto AV, Ivanovic DM (2013) Factores de riesgo cardiovascular en estudiantes universitarios. Rev Chil Nutr 40: 391-396.

13. Jolliffe C, Janssen I (2007) Development of Age-Specific Adolescen Metabolic Syndrome Criteria That Are Linked to the Adult Treatment Pane III and International Diabetes Federation Criteria. J Am Coll Cardiol 49: 891 898.

14. Cristina Beck C, da Silva Lopes A, Gondim Pitanga FJ (2011) Indicadores antropométricos como predictores de presión arterial elevada en adolescentes. Arq Bras Cardiol

15. Sáez Y, Ivonne Bernui I (2009) Prevalencia de factores de riesgo cardiovascular en adolescentes de instituciones educativas. An Fac med 70 259-265.

16. Restrepo de Rovetto C, Agudelo JC, Conde LH, Pradilla A (2012) Presión arterial por edad, género, talla y estrato socioeconómico en población escolarizada de Cali, Colombia. Colomb Med 43: 63-72.

17. Abraham W, Blanco G, Coloma G, Cristaldi A, Gutiérrez N, et al. (2013) ERICA Estudio de los factores de riesgo cardiovascular en adolescentes. Rev Fed Arg Cardiol 42: 29-34.

18. Gooding HC, McGinty S, Richmond TK, Gillman MW, Field AE (2014) Hypertension awareness and control among young adults in the National Longitudinal Study of Adolescent Health. J Gen Intern Med 29: 1098-1104.

19. I Ortiz-Galeano, P Franquelo-Morales, B Notario-Pacheco, JA Nieto
Rodríguez, MV Ungría Canete, et al. (2012) Prehipertensión arterial en adultos jóvenes. Rev Clin Esp 212: 287-291.

20. Goldhaber-Fiebert JD, Rubinfeld RE, Bhattacharya J, Robinson TN (2013) Wise The Utility of Childhood and Adolescent Obesity Assessment in Relation to Adult Health. Med Decis Making 33: 163-175.

21. Martínez MA, Leiva A M, Sotomayor C, Victoriano T, Von Chrismar AM, et al. (2012) Factores de riesgo cardiovascular en estudiantes de la Universidad Austral de Chile. Revistamédica de Chile 140: 426-435.

22. Rodríguez DL, Elena Díaz SM, Ruiz ÁV, Hernández HH, Herrera GV, et al. (2013) Cardiovascular risk factor and their relationship with the hypertension in adolescents. Revista Cubana de Medicina 53: 25-36.

23. Esquivel Lauzurique M, Rubén Quesada M, González Fernández C, Rodríguez Chávez L, Tamayo Pérez V (2011) Curvas de crecimiento de la circunferencia de la cintura en niños y adolescentes habaneros. Rev Cubana Pediatr 83: 44-55.

24. Ogden CL, Margaret D, Carroll MD, Kit BK, Flegal KM (2012) Prevalence of Obesity and Trends in Body Mass Index Among US Children and Adolescents, 1999-2010. JAMA 307: 483-490.

25. Acosta García E, Diamela Carías D, Páez Valery M, Naddaf G, Domínguez Z (2012) Excesso de peso, resistência à insulina e dislipidemia em adolescentes. Acta Bioquím Clín Latinoam 46: 365-373.

26. Bojorges Velázquez LA, Castillo Herrera JA, Jiménez Tamayo R (2013) Risk factors of metabolic syndrome among students from Pablo Guardado Chávez University, 2013. REF PUB: RevistaCubana de Investigaciones Biomédicas 32: $379-388$.

27. Papathanasiou G, Zerva E, Zacharis I, Papandreou M, Papageorgiou E, et al. (2015) Association of High Blood Pressure with Body Mass Index, Smoking and Physical Activity in Healthy Young Adults. Open Cardiovasc Med J 9: 5-17.

28. Piazza N (2005) La circunferencia de la cintura en los niños y adolescentes. Arch Argent Pedriatr 103: 5

29. (2003) Encuesta Nacional de Salud. Ministerio de Salud. República de Chile

30. Benowitz NL, Gourlay SG (1997) Cardiovascular toxicity of nicotine: Implications for nicotine replacement therapy. J Am Coll Cardiol 29: 1422 1431.

31. Lucini D, Bertocchi F, Malliani A, Pagani M (1996) A controlled study of the autonomic changes produced by habitual cigarette smoking in healthy subjects. Cardiovascular Res 31: 633-639. 